\title{
Biomass Allometric Equations of Naturally Growing Cedrus deodara in Dry'Temperate Forests Ecosystems
}

\section{Abdul Raqeeb ${ }^{1,3}$, Syed Moazzam Nizami ${ }^{2,4 *}$, Aamir Saleem³, Lubna Ansari', Saeed Gulzar ${ }^{3}$, Basit Ali ${ }^{3}$, Masooma Saleem ${ }^{5}$}

${ }^{1}$ Gilgit Baltistan Forest Department, Government of Gilgit Baltistan, Pakistan; ${ }^{2}$ Integrated Mountain Area Research Center, Karakoram International University Gilgit Baltistan 15100 Pakistan; ${ }^{3}$ Department of Forestry and Range Management, Arid Agriculture University Rawalpindi 46200 Pakistan; ${ }^{4}$ Department of Forestry, Karakoram International University Gilgit, 15100, Gilgit Baltistan, Pakistan; ${ }^{5}$ Forest Education Divison, Pakistan Forest Institute Peshawar.

\begin{abstract}
In the recent past much of the stress has been given to the tree allometrics, above and below ground biomass and carbon sequestration databases to support the verification and development of greenhouse gas inventories under land use, land use change forestry (LULUCF). In this regard, empirical data of particular species for a specific forest ecosystem is of utmost importance. In the present study volume and biomass allometric of naturally growing Cedrus deodara tree in dry temperate regions of Himalaya has been developed from the empirical data collected from four different locations with three sites each as representative of its naturally growing area. Destructive sampling including excavation of roots was carried for overall 60 trees. The results revealed generic equations for above ground biomass and volume. However, statistical analysis pointed out several significant differences in biomass allocation among $C$. deodara tree due to stand characteristics, highlighting the role and importance of microenvironment in regional and national forest inventories. The study provides a comprehensive tool for estimating volume and biomass, thereby resulting in an accurate assessment of carbon sequestration and stocking in cedar dominated forest ecosystem in the region.

Received | January 06, 2019; Accepted | March 13, 2020; Published | July 26, 2020

*Correspondence | Syed Moazzam Nizami, Integrated Mountain Area Research Center, Karakoram International University Gilgit Baltistan 15100 Pakistan; Email: director.imarc@kiu.edu.pk

Citation | Raqeeb, A., S.M. Nizami, A. Saleem, L. Ansari, S. Gulzar and B. Ali. 2020. Biomass allometric equations of naturally growing Cedrus deodara in dry temperate forests ecosystems. Pakistan Journal of Agricultural Research, 33(3): 498-507.

DOI | http://dx.doi.org/10.17582/journal.pjar/2020/33.3.498.507

Keywords | Temperate forests, Allometric equation, Biomass, Volume
\end{abstract}

\section{Introduction}

$\mathrm{T}$ he need for estimating tree volume, biomass, and carbon stocks is of utmost importance not only in the commercial exploitation of timber but also in the global carbon cycle. Especially in the context of climate change these estimations with sufficient accuracy are pre-requisite for assessing the dynamics of carbon storage in particular ecosystems (Correia et al., 2010). All the carbon sequestration projects that deal with the accrual and long-term carbon sequestration estimation in vegetation and soil organic matter are dependent on these estimates. A better understanding of terrestrial carbon dynamics, and the valuable information and evidence generated by these project help in addressing the physical, natural, social and economic aspects of climate change in a more realistic way (Levy et al., 2004).

Tree allometry establishes quantitative relations between some key characteristic dimensions of trees (usually fairly easy to measure) and other properties (often more difficult to assess). To the extent, these statistical relations established on the 
basis of detailed measurements on a small sample of typical trees, hold for other individuals, they permit extrapolations and estimations of a host of dendrometric quantities on the basis of a single (or at most a few) measurements (Cutini et al., 2013).

The study of allometry is extremely important in dealing with measurements and data analysis in the practice of forestry. The allometry studies the relative size of organs or parts of organisms whereas; tree allometry narrows the definition to applications involving measurements of the growth or size of trees. Allometric relationships are often estimating difficult tree measurement, such as volume, from an easily measured attribute such as diameter at breast height $(\mathrm{DBH})$. The use of allometry is widespread in forestry and forest ecology. In order to develop an allometric relationship there must be a strong relationship and an ability to quantify this relationship between the parts of the subject measured and the other quantities of interest (Smith and Brand, 1983). In addition, when developing these equation(s), growth/ increase in parameters like age, species, site location, etc. must be considered. Once all these guidelines are met, a tempt to develop an allometric equation should be made (Avery and Bukhart, 2002). Use of allometric equations or models is the indirect methods of assessing the tree biomass (Acosta et al., 2002; Figueroa et al., 2010; Zainis et al., 2005). This allometry is developed for entire stand/tree population by estimating the tree dimensions and biomass and applying regression techniques through destructive sampling (Návar, 2010; Birdsey et al., 2013).

Allometric equations have been an important source for estimating biomass and carbon stocks ( $\mathrm{C}$ stocks) of different tree species (Návar, 2010). In the past many allometric relationships have been developed for estimating the total aboveground biomass of a different species or group of species of temperate forests of the world (Aguirre and Jiménez, 2011), or the allocation of biomass and carbon in all individual components as well as in entire trees (Ruiz-Peinado et al., 2011; Rodríguez et al., 2012).

Cedrus deodara (Deodar/Cedar) grows best in mountainous forests, but it is also distributed in various habitats of temperate regions in Himalaya. It strives best at elevational range of $1700-3000 \mathrm{~m}$ in western regions and at $1300-3300 \mathrm{~m}$ in the eastern regions with less dry climate. Its growth is better in alpine lithosols type of soil. In Pakistan deodar/cedar tree exhibits significant cover percentage in dry and moist temperate forests; ultimate contributing in primary productivity and $\mathrm{C}$ stocking of these ecosystems. Under the climatic change scenario when assessments of $\mathrm{C}$ stocks in different forests is becoming need of the day, the role of allometric equations in calculating the $\mathrm{C}$ stocks at species level cannot be denied.

The present study was designed after realizing the need of developing allometric equations for $C$. deodara to estimation of volume, biomass and $\mathrm{C}$ stocks dominated forest ecosystem of Pakistan. So development of the volume and biomass equations for the $C$. deodara growing in natural temperate forests of the Himalaya region in Pakistan was the main objective of the study. The other objective of the study was to integrate and disseminate the information of deodar (the national tree of the country) growing in these inaccessible difficult tracts. For this purpose, the Biomass Expansion factors (BEFs) were also developed to be used in vast scale or regional studies as well as in forest inventories.

\section{Materials and Methods}

\section{Study area}

The study was carried in four different stands of the mixed dry temperate coniferous forest of Chilas Forest Division, Himalaya, Pakistan namely Thore, Hudur, Botogah and Babusar (Figure 1). There is the difference in tree density, composition and structure of these natural stands. The tree density latitude, percentage among the mixture of species, latitude and longitude of the stand have been showed in Table 1 .

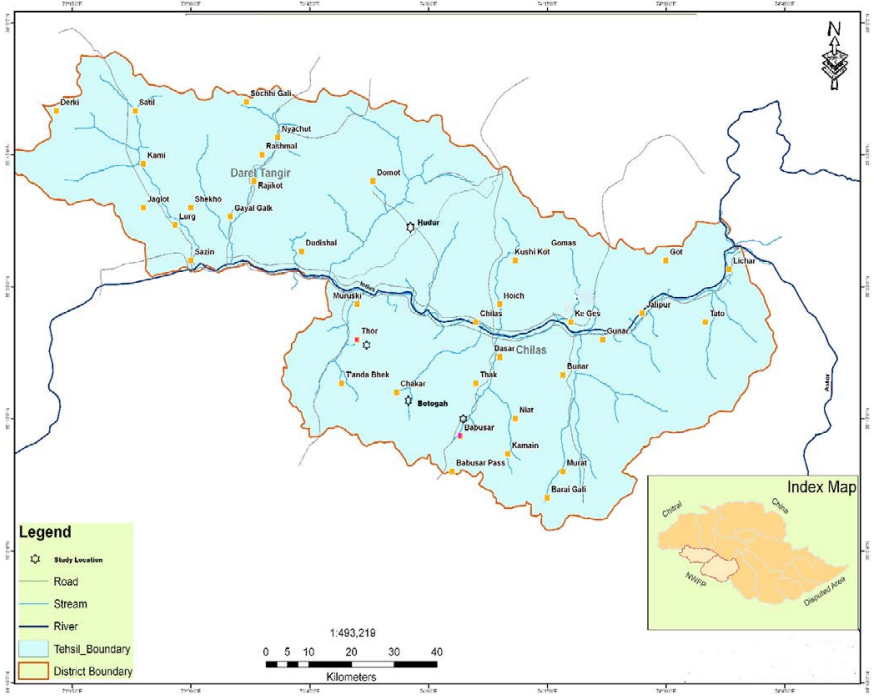

Figure 1: Location of the sampling sites in the study area 
Table 1: Location, tree density, latitude and longitude of the study sites.

\begin{tabular}{|c|c|c|c|c|c|c|}
\hline $\begin{array}{l}\text { Loca- } \\
\text { tion }\end{array}$ & Stand & $\begin{array}{l}\text { Tree } \\
\text { density } \\
\text { ha }^{-1}\end{array}$ & $\begin{array}{l}\text { Density } \\
\text { of Deo- } \\
\text { dar ha-1 }\end{array}$ & $\%$ & Latitude & Longitude \\
\hline \multirow[t]{3}{*}{ Thore } & I & 96 & 39 & 41.46 & $35^{\circ} 23^{\prime} 56^{\prime \prime} \mathrm{N}$ & $73 \circ 52.57 ” \mathrm{E}$ \\
\hline & II & 88 & 20 & 23.17 & $35^{\circ} 21^{\circ} 51^{\prime \prime} \mathrm{N}$ & $73^{\circ} 50 ` 09 " \mathrm{E}$ \\
\hline & III & 75 & 67 & 35.37 & $35^{\circ} 20^{\circ} 48^{\prime \prime} \mathrm{N}$ & $73^{\circ} 49^{`} 11^{\prime \prime} \mathrm{E}$ \\
\hline \multirow[t]{3}{*}{ Hudur } & I & 63 & 36 & 57.14 & $35^{\circ} 37^{\circ} 27^{\prime \prime} \mathrm{N}$ & $73^{\circ} 55^{\circ} 07^{\prime \prime} \mathrm{E}$ \\
\hline & II & 69 & 42 & 60.86 & $35^{\circ} 38^{`} 50^{\prime \prime} \mathrm{N}$ & $73^{\circ} 56^{\circ} 09^{\prime \prime} \mathrm{E}$ \\
\hline & III & 75 & 40 & 53.33 & $35^{\circ} 39^{\circ} 34^{\prime \prime} \mathrm{N}$ & $73^{\circ} 54^{\circ} 03^{\prime \prime} \mathrm{E}$ \\
\hline \multirow[t]{3}{*}{ Batogah } & I & 76 & 44 & 57.88 & $35^{\circ} 19^{\prime} 15^{\prime \prime} \mathrm{N}$ & $73^{\circ} 57^{\circ} 46^{\prime \prime} \mathrm{E}$ \\
\hline & II & 88 & 32 & 36.36 & $35^{\circ} 20^{\circ} 08^{\prime \prime} \mathrm{N}$ & $73^{\circ} 58^{\circ} 32^{\prime \prime} \mathrm{E}$ \\
\hline & III & 89 & 11 & 12.35 & $35^{\circ} 21^{\circ} 05^{\prime \prime} \mathrm{N}$ & $73^{\circ} 59^{\circ} 56^{\prime \prime} \mathrm{E}$ \\
\hline \multirow[t]{3}{*}{ Babusar } & I & 95 & 62 & 65.26 & $35^{\circ} 15^{\circ} 57^{\prime \prime} \mathrm{N}$ & $74^{\circ} 05^{\circ} 04^{\prime \prime} \mathrm{E}$ \\
\hline & II & 98 & 59 & 85.50 & $35^{\circ} 13^{\prime} 59^{\prime \prime} \mathrm{N}$ & $74^{\circ} 07^{\circ} 09^{\prime \prime} \mathrm{E}$ \\
\hline & III & 89 & 57 & 64.04 & $35^{\circ} 12 \cdot 33^{\prime \prime} \mathrm{N}$ & $74^{\circ} 09^{\circ} 02^{\prime \prime} \mathrm{E}$ \\
\hline
\end{tabular}

The elevational range of the study sites varies between $1700-3800 \mathrm{~m}$. The soil is loamy and fairly deep at gentle to moderate slopes. Generally fertile soil is porous and liable to rain water erosion at low vegetation cover sites. The average rainfall is $176.53 \mathrm{~mm}$ (Shiekh, 1993). Most of the precipitation is received in a period between December to May. The climate of the area is mostly dry temperate. The winter temperature goes below to freezing point $\left(-4.44^{\circ} \mathrm{C}\right)$, although in the summer the highest temperature is up to $36.66^{\circ} \mathrm{C}$ (Shiekh, 1993). In the high elevations, winter season is chilling and harsh while the summer is mild. The Deodar ( $C$. deodara) grows in association with Kail (Pinus wallichiana), Fir (Abies pindrow) and Spruce (Picea smithiana) at higher elevations. On the other side at lower altitudes it has association of Chilgoza (Pinus gerardiana), Toot (Morus alba) and Oak (Quercus ilex), Juniper (Juniperous macropoda) (Iqbal, 2001).

\section{Data collection}

A destructive sampling technique was adopted in this study. Before harvesting the trees, their height and the diameter at breast height $(\mathrm{DBH})$ were measured. These measurements were carried out in all the sample sites at each stand. The truly representative trees for height and $\mathrm{DBH}$ of the plot were selected for harvesting. These trees were in the $(\mathrm{DBH})$ range of 10 to $50 \mathrm{~cm}$.

Over all 60 trees, 15 in each location and 5 in each stand were selected for harvesting to gather the data regarding volume, biomass, and basic wood density
(BWD) and biomass expansion factors (BEF). Once the trees were harvested they were separated into stump, stem portion and all the living and dead branches. Later on all the branches were also separated from the main stem. After harvesting the trees, all the dimensions including (DBH, stem height (length from base of the tree to the base of the crown) and total height (length from the base of the trees to the top of the crown) were re-measured to avoid errors. Additionally, the taperness (Form factor ' $F$ ') of the tree was determined by measuring the diameter from base to the top of the tree keeping the gap of $1 \mathrm{~m}$. Basic wood density and oven dried weight was determined by taking a subsample. For this purpose, a disc shaped samples of wood from butt portion (base) at $\mathrm{DBH}$ point and at half height of the main stem were logged to bring to the laboratory.

Division of the each component of tree was carried out as: (a) Twigs and needles biomass: having diameter 1-3 cm): (b) branches and sub branches having diameter $>3 \mathrm{~cm}$ ); (c) main stem. A portable digital balance was used to determine the fresh weight of all the components including branches, sub-branches, and needles right in the field. Later on, a sample of each component was brought to graduate student's laboratory of the department of Forestry and Range Management, Arid Agriculture University Rawalpindi Pakistan for oven drying at $85^{\circ} \mathrm{C}$ till a constant weight has been achieved. The normal time taken by the samples in attaining the constant weight was 4-6 days approximately. Then finally the ratio from dry-to-fresh weight and the dry weight were calculated for each biomass component.

\section{Assessment of the stem volume and biomass}

The volume of the stem was estimated by the help of the following formula (Philip, 1994):

$$
\text { Stem volume } \left.\left(m^{3}\right)=\pi / 4 x d^{2} x h x f \quad \ldots . . \text { (Eq. } 1\right)
$$

Where; " $\pi$ " having value 3.1415 , "d" denotes the $\mathrm{DBH}$, " $h$ " is the length of the stem of tree in meters and " $\mathrm{f}$ " is the average taperness in the main stem or form factor.

The average basic wood density (BWD) was used to determine the stem biomass. The BWD was estimated from the wood samples taken from harvested trees. The stem biomass was derived by using following formula:

$\operatorname{StemBiomass}(\mathrm{Kg})=\operatorname{Stem} \operatorname{Volume}\left(\mathrm{m}^{3}\right) / W D\left(\mathrm{~kg} / \mathrm{m}^{3}\right) \ldots(\mathrm{Eq} .2)$ 
The photosynthesis biomass that includes the biomass of all the tree components including branches, sub branches, twigs and needles was derived considering the dry to green weight ratio and multiplying it with total green weight. Finally, the sum of the biomass of the entire component resulted in total aboveground biomass.

Table 2: Regression Coefficient of reduced Major Axis (RMA) for height and diameter at breast height (DBH) by using log transformation. Regression expression used was $\ln (H)=\ln (a)+b \ln (D)$. Coefficient of determination, Standard error (SE), root mean square errors and regressions probs. have also represented.

\begin{tabular}{llllllllll}
$\begin{array}{l}\text { Loca- } \\
\text { tions }\end{array}$ & \multicolumn{1}{l}{$\operatorname{Ln}(\mathbf{a})$} & $\mathbf{a}$ & $\mathbf{b}$ & \multicolumn{3}{c}{$\mathbf{S E} \ln (\mathbf{a})$} & $\mathbf{S E}(\mathbf{b})$ & $\mathbf{R}^{2}$ & \multicolumn{2}{c}{ RMSE Prob } \\
Thore & 0.43 & 1.59 & 0.54 & 0.2 & 0.08 & 0.79 & 0.08 & 0.01 \\
Hudur & 2.94 & 19.4 & -0.0006 & 0.19 & 0.04 & 0.0004 & 0.05 & 0.42 \\
Botogah & 2.29 & 9.44 & 0.14 & 0.19 & 0.04 & 0.22 & 0.04 & 0.02 \\
Babusar & 2.01 & 7.48 & 0.11 & 0.14 & 0.05 & 0.07 & 0.09 & 0.04
\end{tabular}

Height-Diameter (H-D) model and basic wood density Basic wood density (BWD; $\mathrm{kg} \mathrm{m}^{-3}$ ), which can be obtained by dividing the dry biomass $(\mathrm{kg})$ of the wood sample with its volume $\left(\mathrm{m}^{3}\right)$. For this purpose, wood samples taken from the stem portion were used to calculate BWD. Oven dried volume of the sample was measured mathematically, and oven dried weight of samples was attained by weighing after oven drying at $85^{\circ} \mathrm{C}$ till constant weight.

An average BWD value of each harvested tree was determined. In order to develop the non-linear H-D models $\log$ transformation of both $\mathrm{H}$ and $\mathrm{D}$ was carried. The investigations were also carried out to know how the forest structure and number of trees $\mathrm{ha}^{-1}$ (tree density) affects the height curves. Statistical comparison for the allometry of different stands was tested by applying analysis of covariance (ANCOVA).

\section{Volume and biomass allometry}

In order to derive the volume equation, following formula was used:

$$
V=a\left(D^{2} H\right) \quad \ldots(\text { Eq. } 3)
$$

Where; $D$ represents the $\mathrm{DBH}(\mathrm{cm}), a$ is the scaling coefficient and $H$ is the total height (m).

Assuming, both $D$ and $H$ are not independent variable and are subject to measurement errors and natural variation (Kaitaniemi, 2004). To get the "a" the scaling coefficient in Equation 2; a regression model with reduced major axis (RMA) was taken under consideration leaving the ordinary least squares (OLS) regression.

We selected adopted linear relation approach for volume prediction because this approach has been used at global level in most of the countries (Alberti et al., 2005). Moreover, this approach has now been in use for national and regional forest inventories at global level (Tabachhi and Gasparini, 2011). In this study, the volume equation which was converted into linear form was compared with one given in the working plan of the Chilas forest division. Later was derived from the volume table of $C$. deodara given in working plan (Iqbal, 2001). Generally, power function mathematical models are in vogue for biomass estimations in forestry; therefore, we adopted the same (after considering the initial checks of fit) for biomass allocation (Zianis et al., 2005):

$$
Y=a X^{b} \ldots(\mathrm{Eq} \cdot 4)
$$

\section{Where;}

$Y$ is representative of total biomass of the tree $(\mathrm{kg})$ or the biomass of any individual component, $X$ is the value of variable (may be $D B H$ and $H$ ) while $a$ and $b$ are the coefficients. The $D B H$ generally used as predictor variable of a single tree dimension. In this study DBH was used as $1^{\text {st }}$ tree dimension variable for estimating tree biomass. Additionally, the influence of $\mathrm{H}$ (tree height) as $2^{\text {nd }}$ independent variable was also investigated. As a standard, the values of $a$ and $b$ coefficients are determined by using a linear model which was developed after the log-transformation of $X$ and $Y$ (Zianis and Mencuccini 2004):

$$
\operatorname{Ln} Y=\ln a+b \ln X \ldots \ldots(\text { Eq. 5) }
$$

This transformation can be used only for the case when standard deviation (SD) of $Y$ increases at any $\mathrm{X}$ (Ketterings et al., 2001). If it is the case, more accurate values of $\mathrm{Y}$ will be attained at lower rather than high values of $\mathrm{X}$ (Zar, 1996). In the present study, transformation of the data was carried out to determine values for $\ln a$ and $b$ (Zianis and Mencuccini, 2004). Moreover, as a pre-requisite of the regression model, the homoscedasticity of the transformed data was retrieved by $\log$ transformation (Zianis and Mencuccini, 2004). 
Table 3: Estimated Values of the volume and biomass in each location. Note: Figure in parenthesis representing (standard deviation), $R M A=$ linear regression (equation No:5) reduced major axis and $N L=$ non-linear regression.

\begin{tabular}{lllllll} 
Item & Components & Parameters & Locations & \\
& & & Thore & Hudur & Botogah & Babusar \\
Volume $\left(\mathrm{m}^{3} \mathrm{ha}^{-1}\right)$ & Stem Volume $(\mathrm{GoGB}, 2001)$ & $\mathrm{V}=0.041\left(D^{2} H\right)-0.40$ & $111.1(0.9)$ & $310(6.7)$ & $252(6.2)$ & $181.5(0.9)$ \\
& Stem Volume (Current study $)$ & $\mathrm{V}=0.038\left(D^{2} H\right)$ & $112.9(0.9)$ & $300.1(6.7)$ & $254.0(6.2)$ & $181.9(0.9)$ \\
Biomass $\left(\mathrm{Mg} \mathrm{ha}^{-1}\right)$ & Aboveground & RMA & $108.9(0.9)$ & $237.5(9.2)$ & $193(3.3)$ & $149(0.8)$ \\
& & NL & $114.5(0.9)$ & $236.9(9.2)$ & $193(3.4)$ & $154.9(0.9)$ \\
& \multirow{2}{*}{ Stem } & RMA & $78.9(0.8)$ & $169.1(2.7)$ & $139(3.4)$ & $104.9(0.5)$ \\
& \multirow{2}{*}{ Stem + branches } & NL & $85.9(0.8)$ & $160.1(2.9)$ & $134(4.2)$ & $119.4(0.5)$ \\
& \multirow{2}{*}{ Twigs \& leaves } & RMA & $92.3(0.8)$ & $216.1(3.2)$ & $173(4.4)$ & $124.6(0.9)$ \\
& & NL & $99.9(0.7)$ & $204.7(3.4)$ & $165.6(4.2)$ & $131.3(0.8)$ \\
& & RMA & $17.7(0.2)$ & $26.1(0.6)$ & $22(0.4)$ & $29.4(0.1)$ \\
& & NL & $17.2(0.1)$ & $19.7(0.4)$ & $21.6(0.2)$ & $27.3(0.2)$
\end{tabular}

However, both the Equation 4 and 5 are not statistically identicalbut mathematicallythelog transformed datais equal in both. To bevery rational, when $\ln Y$ was brought to its original scale, a systematic biased is produced. Moreover, many protocols have been proposed to get rid of bias in logarithmic regression estimates (Kaitaniemi, 2004; Zianis and Mencuccini, 2004).

The Log transformation (Equation 5) was first carried out to get the estimated scaling coefficients. Additionally, to incorporate the uncertainties regarding $\mathrm{X}$ variable, $\mathrm{RMA}$ regression analysis was performed in this case. Later, assuming as additive error the Gauss-Newton iterative method was used to calculate the scaling coefficients (Payandeh 1981). It was supposed that the additive property was ensured by nonlinear procedure (Parresol, 1999). A relative difference $(R D)$ was applied to check the performance of each model in determining value of biomass:

$$
R D=[y-\bar{y} / y] \ldots(\text { Eq. } 6)
$$

\section{Where;}

$y$ represents actual variables of volume or biomass; and $\hat{y}$ denotes the predicted variable of volume or biomass. The coefficient of determination $\left(\mathrm{R}^{2}\right)$ and root mean squared error (RMSE) were also calculated. Statistical software $\mathrm{R}$ version 2.13.1 (R Development Core Team, 2011), an improved "lmodel2" package uploaded was used to perform all statistics on the data.

\section{Root sampling}

The stump portion of the 2 trees was excavated at each study sites in selected location of Chilas Forest Division, to determine root biomass. More excavations were not performed at each site due to some regulatory constraints as well as laborious work in this terrain. It was assumed that the roots covered the same mean horizontal area as crown of the tree, neglecting differences in natural overlap. The stump of the selected trees was removed by digging soil around the tree stump to the depth of roots maximum penetration. In the case of $C$. deodara it was approximately $1.5 \mathrm{~m}$. The collection of the roots was carried out as per depth and soil horizon. At each depth (with difference of $20 \mathrm{~cm}$ ), roots were cut with cutter and axe, collected, washed and oven dried at Arid Agriculture University Laboratory. Finally, diameter was measured with digital calliper and roots were categorised as: (i) fine roots having diameter between $0-2 \mathrm{~cm}$; (ii) coarse roots having diameter $>2$ c) and (iii) the taproot.

In the field, portable digital scale was used to determine green/fresh weight of the roots. Some representative samples of the components were oven dried at $85^{\circ} \mathrm{C}$ till the constant weight after bringing them to laboratory. Later on, the ratio between fresh and dry weight was also determined. Finally, the multiplication of dry and fresh weight with the total fresh weight of the components resulted in total biomass.

\section{Biomass expansion factors (BEFs)}

$\mathrm{BEF}$ of the above ground components were also calculated to cope with the limited sampling of the roots. This was achieved by the mathematical division of the value of total aboveground biomass with the value of stem volume and biomass (Gracia et al., 2002). The data of overall 8 trees was used in deriving the root shoot ratio (RSR) and root biomass ratio (RBR). 
This data was collected from the excavation of the stumps and root of these trees till the depth of $1.5 \mathrm{~m}$. The RSR was attained by the mathematical division of the root biomass with the total aboveground biomass while the division of the root biomass with the total above and belowground biomass resulted in value of RBR.

\section{Results and Discussion}

\section{The relationship between height-diameter and basic wood} density

The data revealed that BWD of $C$. deodara was 572 $\pm 9 \mathrm{~kg} \mathrm{~m}^{-3}$ in the entire forest stand. The one way ANCOVA showed that there was non-significant difference in BWD among the sites and also there was non-significant correlation with $\mathrm{D}$ and $\mathrm{H}$. Additionally, the one way ANCOVA also pointed out that height did not affected BWD as it was not significantly varied with $\mathrm{H}$. But power function of $\mathrm{log}$ transformed data of all the sites showed significant effect $(\mathrm{p}<0.01$, ANCOVA) on H-D relationship. For instance, structural types in the Hudur and Botogah study sites also indicated significant effect $(p<0.05$, ANCOVA) on H-D relationship. Due to this reason, separate $\mathrm{H}-\mathrm{D}$ equations were calculated after taking $\log$ of both $\mathrm{H}$ and $\mathrm{D}$ for each sites and structural type (Table 2). For the log transformed data the Thore sites, predicted highly correlated $\mathrm{H}$ and D; while the Babusar and Botogah represented lower correlations because of the lowest co-efficient of determination $\left(\mathrm{R}^{2}\right)$ values. On the other side, both of these variables showed statistically significant correlation. The worst results were showed by Hudur site (Table 2). The reason of this may be effect of natural seeding stand structure and the local pressure.

\section{The allometric equations}

The ANCOVA indicated the volume estimates neither affected by site nor by the structural type. However, for the entire sites a general volume equation was developed. The following form of equation was taken by RMA linear model II $\left(n=60, R^{2}=0.98, p=0.01\right)$ :

$$
V=0.038\left(D^{2} H\right) \ldots \ldots(\text { Eq. } 7)
$$

Where;

$V$ represents volume $\left(\mathrm{m}^{3}\right), \mathrm{D}$ is the diameter at breast height $(\mathrm{m})$ and height of the tree is denoted by $\mathrm{H}(\mathrm{m})$. The measured volume results of each stand sampled in this study has been presented in (Table 3). The goodness-of-fit statistics performed for volume and biomass ( $n=60$ trees) data from the residual analysis for entire location and sites is presented in Table 4. The study also pointed out if $\mathrm{H}$ is removed from linear equation then it results in reduced accuracy of volume prediction $\left(n=60, R^{2}=0.91, p=0.01\right)$ :

$$
V=0.76\left(D^{2}\right) \ldots \ldots(\text { Eq. } 8)
$$

The value of D in Equation 8 was $52.49 \%$ on average basis. It was also noticed increase in $\mathrm{D}$ value of all component's biomass resulted in an increased SD (Figure 2). The log transformation of the entire data was also performed as par Equation 5. All the biomass components and sites did not show any significant (ANCOVA, $\mathrm{p}<0.01$ ) interactions, except for the biomass of twigs and needles (photosynthetic biomass). Also the Hudur and Botogah study locations did not showed any interactions of biomass components and structural type (ANCOVA, $\mathrm{p}<0.05$ ). Due to this reason, all biomass components from entire sites data were predicted using generalized equations excluding twigs and needles (Photosynthetic components). The photosynthesis components of each site and structural type were modelled separately (Table 5). Consequent upon the limited root sampling the total above and below ground biomass was excluded from the analysis.

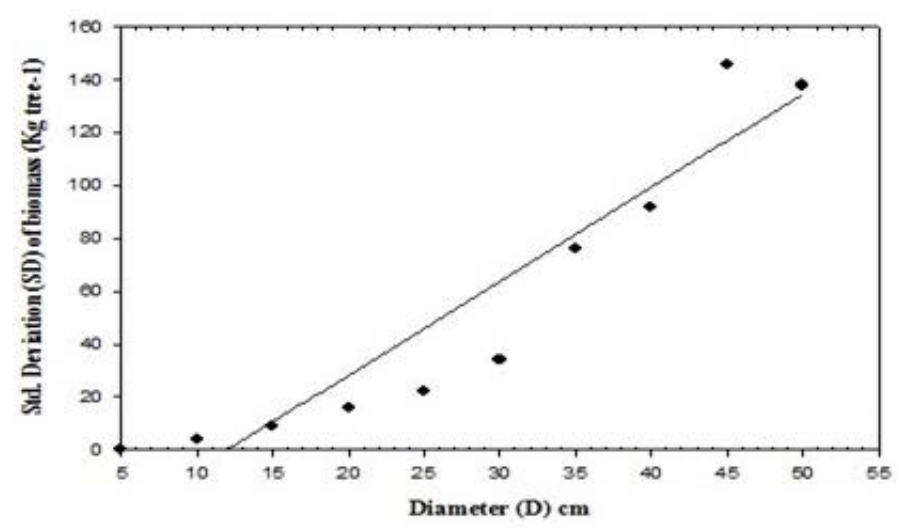

Figure 2: Relationship of diameter and standard deviation of biomass ( $\mathrm{Kg}$ tree-1) at each $5 \mathrm{~cm}$ interval

The non-linear Gauss-Newton iterative procedure was followed to estimate nonlinear regression coefficients. For this purpose, Equation 4 was used to obtained input coefficients and results have been presented in (Table 5). Good estimates were resulted from both the approaches. Both the approaches resulted in less $\mathrm{RD}$ values on average basis (<31\%), even excluding the component of biomass (Table 4). For the entire data, measured biomass was underestimated by linear 
regression, while the non- linear regressions resulted in overestimates for the measured biomass, taking into account either particular component biomass or the total aboveground biomass. Regardless of relatively small variation in the biomass estimates, the lower RMSE brought up more accuracy with the nonlinear method than the linear method. The addition of $\mathrm{H}$ in all the equations did not resulted with any effect on increasing $\mathrm{R}^{2}$ and decreasing $\mathrm{RMSE}$.

Table 4: Statistics of the residual analysis of Volume ( $n=60)$ using Linear (RMA) and Non Linear procedure.

\begin{tabular}{|c|c|c|c|c|c|}
\hline Components & Parameter & Data limit & $\mathbf{R}^{2}$ & RMSE & RD \\
\hline \multirow[t]{2}{*}{ Volume } & GoGB,2001 & All sites & 0.97 & 62.50 & 0.08 \\
\hline & Present study & All sites & 0.98 & 55.53 & 0.08 \\
\hline \multirow[t]{2}{*}{ AGB } & RMA & All sites & 0.97 & 97.20 & 0.16 \\
\hline & NL & & 0.92 & 96.57 & 0.19 \\
\hline \multirow{8}{*}{$\begin{array}{l}\text { Twigs and leaves } \\
\text { biomass }\end{array}$} & RMA & Thore & 0.71 & 4.39 & 0.19 \\
\hline & NL & & 0.90 & 3.90 & 0.24 \\
\hline & RMA & Hudur & 0.63 & 11.70 & 0.17 \\
\hline & NL & & 0.69 & 16.39 & 0.32 \\
\hline & RMA & Botogah & 0.96 & 2.49 & 0.14 \\
\hline & NL & & 0.84 & 2.79 & 0.17 \\
\hline & RMA & Babusar & 0.86 & 5.19 & 0.12 \\
\hline & NL & & 0.96 & 4.94 & 0.15 \\
\hline \multirow[t]{2}{*}{ Stem biomass } & RMA & All sites & 0.91 & 76.99 & 0.24 \\
\hline & NL & & 0.87 & 70.84 & 0.26 \\
\hline \multirow{2}{*}{$\begin{array}{l}\text { Stem and } \\
\text { branch biomass }\end{array}$} & RMA & All sites & 0.92 & 87.93 & 0.21 \\
\hline & NL & & 0.91 & 88.14 & 0.20 \\
\hline
\end{tabular}

\section{The root sampling}

The highest contribution in root biomass was exhibited by tap root $(56.4 \%)$. The second highest contribution $(23.3 \%)$ was from coarse roots while fine roots and hypogeal stump contributed (9.7\%) and (10.6\%) respectively. A range of 0.10 to 0.44 (average $0.24 \pm 0.04$ ) was showed by RSR while the RBR showed a range of 0.09 to 0.40 (average $0.19 \pm$ 0.01). However, no significant correlation was found between RSR and D or between RBR and D. On the other side both showed decreasing trend with increasing $\mathrm{D}$.

\section{Biomass expansion factor (BEF)}

$\mathrm{BEF}$ for the total aboveground biomass was calculated from the nonlinear equations of biomass and linear Equation 7 of volume. Based on stem biomass, the $\mathrm{BEF}$ values were found in the range of 1.39 to 1.44 (average \pm standard error: $1.49 \pm 0.09$ ) while based on stem volume it ranged between and from 0.79 to 1.04 (average \pm standard error: $0.89 \pm 0.04$ )

The BWD of the $C$. deodara determined in this study closely resembles the value reported in the literature (Shiekh, 1993). Comparatively lower heighted trees in Thore site were found and they showed satisfactory correlation between $\mathrm{H}$ and $\mathrm{DBH}$. It is already reported that that $C$ deodara shows slow height growth in the habitat where it is enjoying limited natural resources and competition with associated species (Champion et al., 1965). The normal ranges of height attain by $C$. deodara 45 to $60 \mathrm{~m}$ but in these habitats it can only grow up to $50 \mathrm{~m}$ (Shiekh, 1993). Therefore, it is can be accepted that $C$. deodara would show relatively inaccurate low $\mathrm{H}-\mathrm{DBH}$ function due to low height growth pattern, especially in tall trees where height will culminate earlier than diameter. This is also consistent with Ryan et al. (1997). Moreover, in the Botogah site the stand structure and applied forestry operations are most likely affecting tree height curves as predicted from low values of $\mathrm{R}^{2}$. Currently natural seeding is resulting in good regeneration and as a result uniform growth patterns in stand trees can be seen, in spite of the growth in diameter of individual trees. This may be the reason due to which nonsignificant correlations were found in $\mathrm{H}-\mathrm{DBH}$. It is suggested that as explanatory variable in allometric equations the reliability of $\mathrm{H}$ in $C$. deodara should be carefully evaluated.

The results indicated that volume allometry closely resembles with that given in the working plan of the Chilas Forest Division, dry temperate forest of Pakistan (Iqbal, 2001) which were derived after continuous forest inventory. The volume equations developed in this study can also be used for obtaining more comprehensive data for preparation of volume and biomass table in future and also for estimating regional $\mathrm{C}$ stocks under climate change scenario.

The lower rather than high values of $D$ can provide more precise measurement of biomass (Figure 2). However, more variability in biomass values has been explained by diameter. In comparison to the previous studies on conifers, incorporation of $\mathrm{H}$ in biomass equation has resulted in non-significant improvement in variance of the biomass model (Correia et al., 2010; RuizPeinado et al., 2011). Same had been reported by the high correlation between $D$ and $H$ (multicollinearity; (Ketterings et al., 2001; Zianis and Mencuccini, 2003). 
Table 5: Linear reduced major axis and non-linear procedure based Regression coefficients for biomass components and $D B H$.

\begin{tabular}{lllllllll} 
Variables & Parameter & $\mathbf{n}$ & $\mathbf{L n}(\mathbf{a})$ & $\mathbf{a}$ & $\mathbf{b}$ & $\mathbf{R}^{2}$ & SE $\mathbf{l n}(\mathbf{a})$ & SE(b) \\
Above ground biomass & L (RMA) & 45 & -3.34 & 0.034 & 2.69 & 0.97 & 0.21 & 0.09 \\
& NL & 45 & - & 0.052 & 2.52 & - & 0.025 & 0.11 \\
Twigs and leaves biomass & L (RMA) & 45 & -3.81 & 0.022 & 2.27 & 0.88 & 0.32 & 0.10 \\
& NL & 45 & - & 0.009 & 2.53 & - & 0.006 & 0.18 \\
Thore & L (RMA) & 15 & -4.55 & 0.0094 & 2.54 & 0.72 & 0.54 & 0.23 \\
\multirow{5}{*}{ Hudur } & NL & 15 & - & 0.0011 & 3.1 & - & 0.001 & 0.35 \\
\multirow{5}{*}{ Botogah } & L (RMA) & 15 & -10.99 & 0.00001 & 4.19 & 0.64 & 1.14 & 0.42 \\
& NL & 15 & - & 0.0000001 & 5.42 & - & 0.00000 & 0.84 \\
Babusar & L (RMA) & 15 & -5.449 & 0.004303 & 2.68 & 0.96 & 0.50 & 0.19 \\
& NL & 15 & - & 0.01059 & 2.44 & - & 0.01143 & 0.30 \\
Stem biomass & L (RMA) & 15 & -4.019 & 0.01799 & 2.49 & 0.87 & 0.33 & 0.11 \\
& NL & 15 & - & 0.009570 & 2.64 & - & 0.00611 & 0.179 \\
Stem plus branch biomass & L (RMA) & 45 & -3.640 & 0.029 & 2.70 & 0.91 & 0.28 & 0.30 \\
& NL & 45 & - & 0.092 & 2.39 & - & 0.039 & 0.119 \\
& NL & 45 & - & 0.045 & 2.819 & 0.93 & 0.29 & 0.09 \\
& & 45 & -3.38 & 0.022 & 2.60 & - & 0.014 & 0.104
\end{tabular}

The lower explanatory power of $\mathrm{H}$ that $\mathrm{D}$ in this study resulted due to the low correlation between $D$ and $H$. However, the linear equation of volume in the study get improved with incorporation of $H$ (Equation 7); this indicates that choosing linear or power function (the mathematical function) for the allometries of volume and biomass is of utmost importance with respect to selection and inclusion of variable predictors of the tree dimension such as $H$.

The application of the linear method for estimation of biomass using log transformed data (Equation 4) was better than that of nonlinear regression method but both the approaches showed relatively small differences. However, a systematic bias in biomass retrieval was produced by linear method; for instance, a small differences were also noticed by (Beauchamp and Olson, 1973) both for measured and uncorrected estimates. The current study findings are also consistent with their results.

Insensitivity was shown by the resulted total above ground biomass of the present study to stand density and structure. A universal exponent was derived and proposed for tree level by (West et al., 1999) in universal structural model for the vascular network and then applied by (Anfodillo et al., 2006). So in this study using linear and non- linear equation of aboveground biomass, $\mathrm{b}$ exponent resembling universal exponent was also derived $(b=8 / 3)$.
Twigs and needles representing photosynthetic biomass differ significantly in all the sites. This was resulted inclusively because of the varied crown shapes, availability of light and space in all the sites. While calibrating the canopy photosynthesis models, this finding need to be accurately calibrated in future studies. The high contribution in crown biomass occurring in $C$ deodara in these sites has been verified by this study and resulting in high production of cones.

The RSR mean value (0.24) is consistent with other conifer values reported in many studies (Levy et al., 2004; Vande Walle et al., 2005). In Portuguese pine stands Correia et al. (2010) found RSR value equal to (0.30) and later IPCC (2003) reported as (0.32). The present value of $C$. deodara is $100 \%$ equal to the value of stone pine stands in Spain (Ruiz-Peinado et al., 2011; Cutini et al., 2013). The importance of tap root system in $C$. deodara has been pointed out by this study and is consistent with the (Frattegiani et al., 1993). He investigated the taproot functions in conifers as an escape from competition with understory vegetation especially during early phase of rotation.

\section{Conclusions and Recommendations}

Accurate estimations and allometry of volume and biomass is the key to successful and comprehensive studies which target not only carbon as well as nutrient cycling and global change by involving 
forest inventories. This study revealed different stand characteristics are bringing variations in biomass allocation in $C$. deodara growing naturally in temperate regions of the Himalaya Mountains, which had not been addressed earlier. Moreover, the study has given emphasis that in calibrating biomass, the stand dependent factor and equations have much importance. On the other side, this study resulted in development of not only generalized allometric equations for calculation of volume and biomass as well as biomass and carbon factors for naturally growing $C$. deodara in temperate regions. Lastly, the allometry and carbon factors developed in this study can be integrated and extended for the available data of this region in south Asia.

\section{Acknowledgement}

A special gratitude to forest officials of the Gilgit Baltistan Forest Department Pakistan for logistic supports as well as manpower provision in the field work.

\section{Author's Contribution}

Abdul Raqeeb: Conceived idea, Collected data, data entry, did review of literature.

Syed Moazzam Nizami: Technical advisory, Did analysis, Write manuscript.

Amir Saleem: Technical Guidance, Mentorship.

Lubna Ansari: Data entry.

Saeed Gulzar: Collected data.

Mamoona Saleem: Did data analysis, technical advisory, literature, provision.

\section{Conflict of interest}

There is no conflict of interest between authors and the institutions.

\section{References}

Acosta, M.M.J., H.A. Vargas, M.J. Velázquez and B. Etchevers. 2002. Estimación de la biomasa aérea mediante el uso de relaciones alométricas en seis especies arbóreas en Oaxaca, México. Agrociencia. 36: 725-736.

Aguirre, C.O.A. and Y.J.P. Jiménez. 2011. Evaluación del contenido de carbono en bosques del sur de Nuevo León. Rev. Mex. Cien. For. 2: 73-84. https://doi.org/10.29298/rmcf.v2i6.575 Alberti, G., P. Candido, A. Peressotti, S. Turco,
P. Piussi and G. Zerbi. 2005. Aboveground biomass relationships for mixed ash (Fraxinus excelsior L. and Ulmus glabra Hudson) stands in Eastern Prealps of Friuli Venezia Giulia (Italy). Ann. For. Sci. 62: 831-836. https://doi. org/10.1051/forest:2005089

Anfodillo, T., V. Carraro, M. Carrer, C. Fior and S. Rossi. 2006. Convergent tapering of xylem conduits in different woody species. New Phytol. 169: 279-290. https://doi.org/10.1111/ j.1469-8137.2005.01587.x

Avery, A. and D. Burkhart. 2002. Forest Measurements. McGraw-Hill Companies Inc. New York. pp. 236.

Beauchamp, J.J. and J.S. Olson. 1973. Corrections for bias in regression estimates after logarithmic transformation.Ecology.54:1403-1407.https:// doi.org/10.2307/1934208

Birdsey, R., G. Angeles-Perez, W.A. Kurz, A. Lister, M. Olguin, Y.D. Pan, C. Wayson, B. Wilson and K. Johnson. 2013. Approaches to monitoring changes in carbon stocks for REDD. Carbon Manage. 4: 519-537. https://doi.org/10.4155/ cmt.13.49

Champion, H.G., S.K. Seth and G.M. Khattak. 1965. Manual of silvicultural for Pakistan. Pak. For. Inst., GoP, Peshawar.

Correia, A.C., M. Tome, C.A. Pacheco, S. Faias, A.C. Dias, J. Freire, P.O. Carvalho and J.S. Pereira. 2010. Biomass allometry and carbon factors for a Mediterranean pine (Pinus pinea L.) in Portugal. For. Syst. 19: 418-433. https:// doi.org/10.5424/fs/2010193-9082

Cutini, A., F. Chianucci and M.C. Manetti. 2013. Allometric relationships for volume and biomass for stone pine (Pinus pinea L.) in Italian coastal stands. Iforest-Biogeosci. For. 6: 331-335.https://doi.org/10.3832/ifor0941-006

Figueroa, N.C.F., G.P. Angeles, A.M. Velázquez and H.M.P. De los Santos. 2010. Estimación de Biomasa en un bosque bajo manejo de Pinus patula Schltdl. et Cham. en Zacual ᄀtián,. Hidalgo. Rev. Mex. Cien. For. 1: 105-112. https://doi.org/10.29298/rmcf.v1i1.658

Frattegiani, M., M. Mercurio, M. Mencuccini and W. Profili. 1993. Quantitative analysis of stone pine (Pinus pinea L.) root systems morphology and its relationship with water table and soil characters. Invest. Agrar., Sistemas Recur. Forestales. 3: 405-416.

Gracia, C., S.S., Vayreda, J.J. Ibáñez. 2002. 
Abovegorund biomass expansion factors and biomass equations of forests in Catalonia. COST E21 Meeting,, Besalu(Spain) July 2002.

IPCC, 2003. Good practice guidance for land use, land-use change and forestry. Institute for Global Environmental Strategies, Kanagawa, Japan.

Iqbal, M., 2001. Working Plan of the Chilas Forest Division 2001-2012. Page 349 in G. B. F. Department, editor., Gilgit-Pakistan.

Kaitaniemi, P., 2004. Testing the allometric scaling laws. J. Theor. Biol. 228: 149-153. https://doi. org/10.1016/j.jtbi.2003.12.007

Ketterings, Q.M., R. Coe, M. van Noordwijk, Y. Ambagau and C.A. Palm. 2001. Reducing uncertainty in the use of allometric biomass equations for predicting above-ground tree biomass in mixed secondary forests. For. Ecol. Manage.146:199-209.https://doi.org/10.1016/ S0378-1127(00)00460-6

Levy, P.E., S.E. Hale and B.C. Nicoll. 2004. Biomass expansion factors and root : shoot ratios for coniferous tree species in Great Britain. Forestry. 77: 421-430. https://doi.org/10.1093/ forestry/77.5.421

Návar, J., 2010. Measurement and Assessment Methods of Forest Aboveground biomass: A literature review and the challenges ahead. Pages 27-64 in Agosto, editor. Biomass, Rijeka, Croatia.

Parresol, B.R., 1999. Assessing tree and stand biomass: A review with examples and critical comparisons. For. Sci. 45: 573-593.

Payandeh, B., 1981. Choosing regression models for biomass prediction equations. For. Chronical. 57: 229-232. https://doi.org/10.5558/tfc572295

Philip, M.S., 1994. Measuring trees and forests. CAB International Press,, Wallingford, United Kingdom.

R Development Core Team. 2011. R: a language and environment for statistical computing in $\mathrm{R}$ Foundation for Statistical Computing, editor. Vienna,, Austria.

Rodríguez, O.G., H.M.P. de los Santos, V.A. González, H.A. Aldrete, A. Gómez and G.y.G. Fierros. 2012. Modelos de biomasa aérea y foliar en una plantación de pino de rápido crecimiento en Oaxaca. Madera y Bosques. 18: 25-41. https://doi.org/10.21829/myb.2012.1811116

Ruiz-Peinado, R., M. del Rio and G. Montero. 2011. New models for estimating the carbon sink capacity of Spanish softwood species. For. Syst., 20:176-188. https://doi.org/10.5424/ fs/2011201-11643

Ryan, M.G. and B.J. Yoder. 1997. Hydraulic limits to tree height and tree growth. Biosci., 47: 235242. https://doi.org/10.2307/1313077

Shiekh, M.I., 1993. Trees of Pakistan. Pakistan Forest Institute, Peshawar.

Smith, W.B. and G.J. Brand. 1983. Allometric biomass equations for 98 species of herbs, shrubs, and small trees. Research note NC-299. USDA Forest Service, North Central Forest Experiment Station, St. Paul, MN pp. 8.

Tabacchi, G.D.C.L. and P. Gasparini. 2011. Aboveground tree volume and phytomass predictionequations for forest species in Italy. Eur. J. For. Res., 130: 911-934. https://doi. org/10.1007/s10342-011-0481-9

Vande Walle, I., N. Van Camp, D. Perrin, R. Lemeur, K. Verheyen, B. Van Wesemael and E. Laitat. 2005. Growing stock-based assessment of the carbon stock in the Belgian forest biomass. Ann. For. Sci. 62: 853-864. https://doi.org/10.1051/ forest:2005076

West, G.B., J.H. Brown and B.J. Enquist. 1999. A general model for the structure and allometry of plant vascular systems. Nature, 400: 664-667. https://doi.org/10.1038/23251

Zar, J.H., 1996. Biostatistical analysis. Prentice Hall, Englewood Cliffs, NJ, USA.

Zianis, D. and M. Mencuccini. 2003. Aboveground biomass relationships for beech (Fagus moesiaca Cz.) trees in Vermio Mountain, Northern Greece, and generalised equations for Fagus sp. Ann. For. Sci. 60: 439-448. https://doi. org/10.1051/forest:2003036

Zianis, D. and M. Mencuccini. 2004. On simplifying allometric analyses of forest biomass. For. Ecol. Manage. 187: 311-332. https://doi. org/10.1016/j.foreco.2003.07.007

Zianis,D.,P.Muukkonen,M.R. and M.Mencuccini. 2005. Biomass and stem volume equations for tree species in Europe. Silva Fennica. 4: 1-63. 